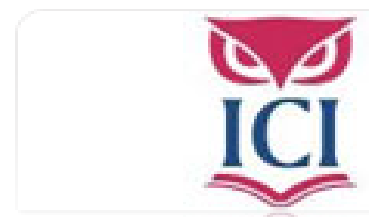

IUS. Revista del Instituto de Ciencias Jurídicas de Puebla A.C.

ISSN: 1870-2147

revista.ius@hotmail.com

Instituto de Ciencias Jurídicas de Puebla A. C.

México

Maraniello, Patricio Alejandro

Las limitaciones económicas al acceso a la justicia

IUS. Revista del Instituto de Ciencias Jurídicas de Puebla A.C., núm. 21, 2008, pp. 98-118

Instituto de Ciencias Jurídicas de Puebla A. C.

Puebla, México 


\section{LAS LIMITACIONES ECONÓMICAS AL ACCESO A LA JUSTICIA*}

Patricio Alejandro Maraniello**

SMARIO

1. Introducción

2. Los diferentes puntos de vista del ordenamiento económico

2.1. Derechos económicos

2.2. Análisis económico del derecho

3. La visión constitucional a la política económica

3.1. El poder judicial en su rol financiero y tributario

4. Acceso a la justicia

4.1. Cuáles son las dificultades y problemáticas principales al acceso a la justicia

4.2. La contraloría social para la defensa del acceso a la justicia

4.3. Situación en América

4.4. La Unión Europea y la nueva ley española 16/05

5. Jerarquización de los derechos económicos, sociales y culturales y los derechos civiles y políticos

6. El solve et repete

7. Limitaciones económicas vedadas y permitidas

8. A modo de conclusión

\section{RESUMEN}

En el presente trabajo abordaré la relación o la influencia que han tenido los derechos económicos, sociales y políticos en el acceso a la jurisdicción. Donde el sistema legal debe permitir y garantizar, en condiciones de igualdad el acceso a la justicia, éste es el paso inicial e insosla-

\section{ABSTRACT}

The present article approaches the relationship or the influence that he/she has been entitled the economic, social and political in the access to the jurisdiction. Where the system legal debit side to allow and to guarantee, under conditions of equality, the access to the justice this it is the initial to the effective concretion of the

* Actualización y ampliación de la ponencia elaborada para el vi Congreso Mundial de Derecho Constitucional, celebrado en la ciudad de Santiago de Chile del 12 al 16 de enero de 2004. Las instituciones organizadoras fueron The International Association of Constitutional Law (IACL-AIDC) y La Asociación Chilena de Derecho Constitucional, entre muchas otras.

** Profesor de grado y posgrado de derecho constitucional en la Facultad de Derecho de la Universidad de Buenos Aires. Profesor de doctorado de la Universidad del Salvador. Profesor de la Escuela del Consejo de la Magistratura Nacional. Profesor de la Escuela de Abogados del Estado. Profesor de posgrado en la Universidad de Morón. Funcionario del poder judicial de la nación. 
yable a la concreción efectiva de los derechos. Pero sabemos que al ser un servicio que presta el Estado, puede requerir el pago previo de una tasa, y que en contraprestación de ello a cada individuo se le brindará el pleno acceso a un tribunal imparcial que analice su derecho reclamado, sin asegurarle un resultado positivo a la petición. Ahora bien, si decimos que el Estado tiene la potestad de imponer una carga tributaria para poder iniciarse una causa, el acceso a la justicia no es libre sino condicionado a la posibilidad de poder afrontar el pago del tributo citado. Así pues se produce un choque de derechos, por un lado lo que denominamos las politicas económicas y los derechos fiscales cuya potestad por parte del Estado radica en obtener recursos para cubrir los gastos que irroguen el funcionamiento mismo del aparato judicial; y por otro los derechos de acceso a la justicia, que tienen todas las personas sin restricciones y en un plano de igualdad. rights. But we know that to the being a service that lends the state, can require the previous payment of a rate, and that in consideration of it to each individual will be offered the full access to an impartial tribunal that analyzes its reclaimed right, without assuring a positive result to the petition. Now then, if we say that the state has the imperium of imposing a tributary load to be able to begin a cause, the access to the justice is not free but conditional to the possibility of being able to confront the payment of the mentioned tribute. Therefore a crash of rights takes place, on one hand what we denominate those political economic and, those fiscal rights whose imperium on the part of the State resides in obtaining resources to cover the expenses that cause the same operation of the judicial apparatus and for other those access rights to the justice that have all the people without restrictions and in a plane of equality. With the importance that you had the access so much to the justice like the economic politicians in a country where the good election of her takes to its prosperity and its growth, while an error in this selection will produce serious social disagreements.

\section{INTRODUCCIÓN}

El sistema legal debe permitir y garantizar, en condiciones de igualdad, el acceso a la justicia; éste es el paso inicial e insoslayable a la concreción efectiva de los derechos.

Pero sabemos que al ser un servicio que presta el Estado, puede requerir el pago previo de una tasa, y que en contraprestación de ello a cada individuo se le brindará el pleno acceso a un tribunal imparcial que analice su derecho reclamado, sin asegurarle un resultado positivo a la petición.

Ahora bien, si decimos que el Estado tiene la potestad de imponer una carga tributaria para poder iniciarse una causa, el acceso a la justicia no es libre sino condicionado a la posibilidad de poder afrontar el pago del tributo citado. 
Así pues, se produce un choque de derechos: por un lado lo que denominamos las politicas económicas y los derechos fiscales, cuya potestad por parte del Estado radica en obtener recursos para cubrir los gastos que irroguen el funcionamiento mismo del aparato judicial; y por otro los derechos de acceso a la justicia que tienen todas las personas sin restricciones y en un plano de igualdad.

Como toda confrontación de derechos, habrá que analizar y resolver cuáles son los límites económicos vedados y cuáles son los límites económicos permitidos del acceso a la justicia.

\section{LOS DIFERENTES PUNTOS DE VISTA DEL ORDENAMIENTO ECONÓMICO}

\subsection{Derechos económicos}

Si debemos elegir dos relaciones que sean tangencialmente indispensables en el desarrollo o progreso de un país, esa relación no sería otra que la existente entre la economía y el derecho.

Dentro de ello podemos citar dos institutos que nacen de esta cuestión y éstos son los denominados derechos económicos y el análisis económico del derecho.

La palabra derecho deriva del latín directus, que significa recto, sin torcerse a un lado ni a otro, mientras que en sentido restringido se hace referencia al ius, término usado en la antigua Roma para diferenciar este tipo de derecho creado por el hombre del derecho sagrado, fas.

Y se relaciona con la economía definiéndola como el conjunto de relaciones jurídicas originadas por la producción, circulación, distribución y consumo de la riqueza, todas tendientes al bienestar general. ${ }^{1}$ Es decir, el derecho económico está formado por las normas jurídicas que, dentro de un marco institucional, regula las actividades del mercado, de las empresas y de los demás agentes económicos. Para realizar las metas y los objetivos de la política económica, el mencionado marco institucional puede ser tanto el de una economía de mercado o como el de un sistema dirigido que funcione a través de decisiones de autoridad social. ${ }^{2}$

Y si para ello le damos preeminencia a la Constitución material y formal, juntamente con sus principios y garantías, estaremos frente al derecho constitucional económico, cuyo fin predominante es el bienestar general;

${ }^{1}$ Facio, Marta de Bello, Teoría general de derecho civil, Universitaria, p. 8.

${ }^{2}$ Bidart Campos, Germán, El orden socioeconómico en la Constitución, Ediar, 1999. 
éste esta referido en el Preámbulo de la Constitución Nacional al expresar "promover el bienestar general", haciendo hincapié en la búsqueda de que todos los habitantes de la nación Argentina puedan vivir de la mejor manera posible, en buenas relaciones de convivencia con sus semejantes y con la mayor cantidad de necesidades básicas satisfechas.

Por ello el Estado, al tener la obligación de establecer criterios para identificar y proteger al habitante menos favorecido, de modo que las diferentes condiciones sociales o culturales de acceso se transformen en una aproximación al ideal de igualdad de acceso a la justicia, son las reglas de los derechos económicos los elementos que mejor se aproximarán a una solución más científica y metodológica.

\subsection{ANÁlisis ECONÓMICO dEL DERECHO}

El análisis económico del derecho (AED), o derecho y economía adquieren especial relevancia en el contexto académico estadunidense a principios de la década de 1960, especialmente a partir de un célebre artículo escrito por el profesor de la Universidad de Chicago, Ronald Coase, ${ }^{3}$ intitulado "El problema del costo social". El AED propone aplicar al estudio y evaluación de las normas jurídicas el método propio de la ciencia económica, considerando los incentivos de aquéllas para alcanzar estados de eficiencia. ${ }^{4}$

En uno de los razonamientos más famosos de la economía del siglo xx, Coase plantea que los mercados alcanzan el equilibrio eficiente siempre y cuando existan derechos de propiedad bien definidos y nos encontremos

\footnotetext{
${ }^{3}$ Coase, Ronald H., "The problem of social cost", Journal of Law and Economics, 1960, p. 1-44. Este trabajo, junto con el también influyente "The nature of the firm" (1937) le valieron a su autor el premio Nobel de Economía en el año 1991. Ronald Coase nació en el año 1910 en Willesden, cerca de Londres. Estudió en la London School of Economies, donde se graduó en 1932, para pasar a la Escuela de Dundee y a la Universidad de Liverpool. En 1951 se doctoró en la Universidad de Londres y luego, en Estados Unidos, trabajó en las universidades de Buffalo y Virginia, hasta que en 1964 se incorporó a la de Chicago. En 1991 recibió el premio Nobel de Economía "por su contribución al esclarecimiento de la importancia de los costes de las transacciones y de los derechos de propiedad económicos, para la estructura institucional y el funcionamiento de la economía". Con la obra de Coase se abren nuevas líneas de investigación que llevan a los economistas a generalizar menos acerca de la necesidad de la intervención del Estado para compensar los efectos externos de las actividades económicas. La negociación de los derechos de propiedad como bienes en el mercado a un precio fijado por la demanda y la oferta hace innecesaria la intervención estatal, para solucionar las distorsiones que provocan las "externalidades" (beneficios sin coste para el que se lucra o, al revés, cargas sin beneficio): tesis que quedó plasmada en el llamado teorema de Coase. Sus obras más significativas son The Nature of the Firm (1932), donde se plantea por qué existen organizaciones del tipo de las empresas y por qué cada empresa tiene el volumen que tiene, y The Problem of Social Coast (1960).

${ }^{4}$ Cracogna, Jerónimo, "Renegociación de contratos de servicios públicos, derecho de propiedad y costo de transacción”, diario El Derecho del 17/02/04.
} 
en ausencia de "costo de transacción". Cabe formular, con carácter previo, una operacionalización de los términos teóricos involucrados en su afirmación. Calificamos un Estado "eficiente", en tanto hayamos alcanzado una situación en la cual no sea posible mejorar la posición de algún agente sin empeorar la de otro. Se trata del conocido criterio de eficiencia de Pareto u optimalidad del Pareto, formulado por el ingeniero italiano homónimo y utilizado, entre otros, por economistas y filósofos políticos. Por su parte, los costos de transacción refieren a los costos propios de todo proceso de negociación, esto es, en líneas generales, búsqueda de una contraparte, debate de los términos del acuerdo, acceso a la información relevante y monitoreo del cumplimiento del convenio. ${ }^{5}$

De ese modo, la ausencia de costo de transacción incentiva a los agentes que actúan en el mercado a involucrarse en negociaciones tendientes a mejorar sus respectivas situaciones y, con ello, maximizar la riqueza en la sociedad. Ahora bien, a efectos del éxito en alcanzar algún acuerdo de esta clase, resulta necesaria la previa definición de derechos de propiedad, pues, de lo contrario, el punto de partida de las negociaciones se vería desdibujado, apareciendo también difusos y poco susceptibles de aplicación sus resultados. En suma, se trata de dos condiciones bajo las cuales florecería un renovado laissez faire y cuya garantía corresponde al Estado. ${ }^{6}$

Coase ha sabido graficar su hipótesis (o teorema, como suele ser presentada por los economistas pese a su ausencia de formulación y demostración como tal) mediante el empleo de ejemplos de transacciones entre particulares ante situaciones de externalidades. ${ }^{7}$ Empero diversos autores dentro del AED y de la economía neoinstitucional han extendido su ámbito de aplicación a intercambios de cualquier índole (dentro y fuera del mercado) entre agentes diversos (incluso del Estado).

\footnotetext{
${ }^{5}$ Cracogna, Jerónimo, Op. cit.

${ }^{6}$ Idem.

${ }^{7}$ Así es el caso de los propietarios de campos vecinos dedicados a la ganadería y a la agricultura, respectivamente. Supongamos que las vacas del primero invaden los terrenos sembrados del segundo, arruinando la producción de éste (externalidad). En contraposición con el tradicional enfoque dado por A. C. Pigou respecto de la internalización de la externalidad que correspondería al ganadero pagar los daños por imposición del Estado (solución aún sostenida por muchos profesores de medio ambiente). Coase propone una alternativa de laissez faire. Ante la ausencia de costos de transacción y la existencia de derechos de propiedad claramente definidos, las negociaciones entre las partes mostrarán alguno de los siguientes resultados: 1) si los costos del daño infligido por los animales a las plantaciones superaran los costos totales de mantenerlos alejados de éstas, las vacas tenderán a permanecer fuera de los campos, 2) si los costos de mantener a los animales alejados de las plantaciones superaran los costos del daño infligido por las vacas, éstas tenderán a permanecer en los campos. En el primer caso, el agricultor pagará al ganadero por mantener a los animales fuera de su terreno; en el segundo será éste quien compense a aquél por el daño causado.
} 
Así pues, estos conceptos deberán ser utilizados en una política económica de un país para llegar a lograr un estado Pareto superior, con beneficios no sectoriales sino para la sociedad entera.

En esta escuela la imposición de una carga tributaria -con las excepciones a todas aquellas que no tengan recursos- resultaría sólo por un acto de necesidad que mejore su funcionamiento sin alterar los recursos del Estado para otras necesidades y se beneficie la mayor cantidad de ciudadanos con el mínimo indispensable del erario estatal.

\section{LA VISIÓN CONSTITUCIONAL A LA POLÍtICA ECONÓMICA}

La Constitución Federal contiene un sistema completo de política económica, en cuanto garantiza, por disposiciones terminantes, la libre acción del trabajo, del capital y de la tierra, como principales agentes de producción, ratifica la ley natural de equilibrio que preside al fenómeno de la distribución de la riqueza y encierra en límites discretos y justos los actos que tienen relación con el fenómeno del consumo público. Toda la materia económica se halla comprendida en estas tres grandes divisiones de los hechos que la constituyen. ${ }^{8}$

Un rasgo muy significativo, es el rol existencial que le dan los economistas a las regulaciones jurídico-normativas; para ello establecen dos tipos de economía, la economía positiva y la economía normativa. La primera, también llamada economía pura o aplicada, se ocupa de las generalidades filosóficas y prácticas, mientras que la segunda es más focalizada hacia sectores determinados o personas o grupos de personas, con grandes rasgos subjetivos, que quizás lo que determine para un sector de la población no sirva para otros y viceversa. Por ejemplo, los montos regulatorios de la actividad docente no pueden resultar igual a la utilizada para los serenos, porque son de rasgos diferentes, pero esto no significa que no tengan regulaciones generales que sí son comunes a todos, como la obligación de tener descanso, vacaciones y seguros sociales.

De estos tipos económicos derivan las leyes que regulan su funcionamiento, y aquí nacen las leyes económicas positivas, donde se buscan explicaciones objetivas del funcionamiento de los fenómenos económicos. Se ocupan "de lo que es o podría ser". Si se dan tales circunstancias objetivamente, tendrán lugar objetivamente tales acontecimientos que

${ }^{8}$ Alberdi, Juan Bautista, Op. cit., Sistema economía y rentístico de la Confederación Argentina, t. ıv, p. 318. Plus Ultra, Buenos Aires. 
revestirán características generales, seguidas por la mayoría de los profesionales de la materia. Mientras, las leyes económicas normativas ofrecen prescripciones para la acción basadas en juicios de valores personales y subjetivos. Se ocupan "de lo que debería ser".

La Constitución nacional, como la ley fundamental de rasgos supremos y generales, se encuentra dentro de las leyes positivas, pues es también ley suprema positiva en materia económica. Como se podrá notar, el rol de ésta resulta amplio y necesario en su desarrollo analítico, en aras de sostener a un sistema que se precie de económico.

Lo que reviste trascendencia en esta temática, es la justiciabilidad de las normas o medidas económicas que dicte tanto el poder ejecutivo como el poder legislativo, pues al tener carácter político la decisión, el poder judicial se encuentra, en principio, limitado en su análisis.

En la división de poderes, donde cada poder ejercer su facultad propia sin intervención de los restantes poderes, también existe un control mutuo que se efectúan entre sí; éstos son los elementos primordiales en un sistema republicano que deben ser respetados, pero ¿cuál es el límite en el control judicial ante decisiones políticas económicas, como el pago de una tasa de justicia? No cabe duda que el límite se centra en que el juez no se transforme en legislador supliendo de ese modo al poder legislativo.

Pero ello no es óbice para que pueda cuestionar todo tributo que limite el acceso a la justicia en situaciones de desigualdad, desde su monto a su existencia misma. Pero, como dijimos, no puede crear uno nuevo, transformándose en legislador.

\subsection{El POdeR JUdicial en SU ROL FinANCIERO Y tributario}

El poder judicial como órgano del Estado, necesita recursos económicos para solventar su funcionamiento. Esto no resulta un tema menor, ya que cuanto mayor sea su autonomía económica, mayor será su independencia ante el resto de los poderes. Ante ello la preocupación más inmediata, además de ejercer su función judicial, es realizar un equilibrio armónico entre sus propios recursos y sus gastos, para de esta forma lograr la verdadera autonomía. Alberdi ${ }^{9}$ decía que "la riqueza importa a la prosperi-

${ }^{9}$ Nacido en Tucumán el 20 de agosto de 1810, poseía un gran conocimiento de la filosofía política y cultural anglosajona, lo que inspiró su conciencia liberal. Por esta razón se afilió de muy joven al Partido Liberal. En sus numerosos escritos analizó la estructura económica y social de su país, criticando la situación de atraso que había creado la colonización española y defendiendo la industrialización inten- 
dad de la nación y a la existencia del poder. Sin rentas no hay gobierno; sin gobierno, sin población, sin capitales, no hay Estado..."

Los recursos del Estado están formados por los tributos -impuestos, tasas y contribuciones-, la renta de la nación, lo obtenido por las ventas del Estado y los empréstitos. Aunque con la distinción que estos últimos son ingresos con características excepcionales e irregulares.

Según el Art. 4 de la Constitución argentina, la contribución es para formar el tesoro nacional; el tesoro, como medio de ejecución, es para gobernar, el gobierno es para hacer cumplir la Constitución.

A su vez la Constitución, como dice el Preámbulo, es para afirmar la unión nacional, afianzar la justicia, consolidar la paz, servir a la defensa común, promover el bienestar y asegurar los beneficios de la libertad. La contribución es, según esto, el precio con que se obtiene el goce de estas cosas; luego su erogación forma el gasto más precioso del hombre en sociedad. ${ }^{10}$

En la misma línea se encuentran los pensamientos de Hamilton, ${ }^{11}$ cuando considera al dinero como "principio vital del cuerpo político, y como tal sostiene su vida y movimientos y lo capacita para cumplir sus funciones más esenciales. Por consiguiente, una facultad perfecta de allegarse con normalidad y suficiencia los fondos necesarios, hasta donde los recursos de la comunidad lo permitan, debe ser considerada como un elemento componente indispensable en toda Constitución. Cualquier deficiencia a este respecto ocasionaría uno de estos dos males: o el pueblo se verá sujeto a un saqueo continuo, en sustitución de otro sistema más recomendable para satisfacer las necesidades públicas o el gobierno se extinguirá en una atrofia fatal y perecerá en breve tiempo..."

El poder judicial se nutre de una clase de los tributos señalados, y éstos son las tasas judiciales, que se encuentran reguladas por la Ley 23898, obligatoria para el ingreso de toda acción judicial, con dos excepciones: una, las enunciadas en el Art. 13 de la citada ley; y quienes se encuentren exentos por la concesión de un beneficio de litigar sin gastos por inicio de algunas de las partes, según lo regulado por el Art. 79ss del CPCCN.

Sin embargo, esta tasa de justicia no es percibida directamente por el poder

siva como única forma posible de progreso. Según Alberdi, la clase capaz de llevar a cabo esa industrialización, la burguesía, no existía en la Argentina, por lo que consideraba imprescindible la inmigración europea. (www.eumed.net/cursecon/economistas/alberdi.htm). Esta última cuestión la encontramos plasmada en el Art. 25 de la Constitución Nacional, donde establece como política inmigratoria, donde determina como una acción positiva el fomento de la inmigración europea.

${ }^{10}$ Idem.

${ }^{11}$ Hamilton, Madison y Jay, El federalista, Libro xxx, Fondo de Cultura Económica, México, p. 119. 
judicial, sino es recaudada por el poder ejecutivo y luego por partidas elaboradas por el Ministerio de Economía (Secretaría de Hacienda) son giradas finalmente a la Corte Suprema de Justicia y al Consejo de la Magistratura.

Todo ello se elabora a través de la Ley de Presupuesto regulada en el Art. 75 inciso 8 de la Constitución Nacional y en la ley de administración financiera.

Esta ley consta de tres etapas:

1) Etapa preparatoria: Comienza la elaboración en los organismos centralizados y descentralizados respectivos y luego pasa al poder ejecutivo nacional (Ministerio de Economía, Secretaría de Hacienda) para la elaboración del proyecto de presupuesto (Art. 20 del Decreto 438/92 y Art. 2 del Decreto 473/02).

2) Etapa de discusión: Es el poder legislativo el que ejerce el control sobre el poder ejecutivo. Este proyecto de ley tendrá como cámara iniciadora la Cámara de Diputados (Art. 52 de la cN).

3) Etapa de ejecución: Nuevamente estará a cargo del poder ejecutivo (Ministerio de Economía, Secretaría de Hacienda) (Art. 2 del Decreto 473/02) y de los organismos del Estado correspondientes.

4) Etapa de fiscalización: Esta última parte es realizada por el poder legislativo a través de la llamada "cuenta de inversión", que nuevamente la Legislatura controla si realmente se ejecutó el presupuesto de acuerdo a la ley presupuestaria de ese año (Art. 75 Inc. 8 de la cN).

El poder judicial en forma totalmente autónoma y sin interferencia alguna, confecciona la etapa iniciadora o vía preparatoria, con los límites que resulte de la ley de presupuesto.

\section{ACCESO A LA JUSTICIA}

El acceso a la justicia es un concepto más amplio que el de la jurisdicción, porque aquella noción condensa un conjunto de instituciones, principios procesales y garantías jurídicas, así como directrices político-sociales, en cuya virtud el Estado debe ofrecer y realizar la tutela jurisdiccional de los derechos de los justiciables, en las mejores condiciones posibles de acceso económico y de inteligibilidad cultural, de modo tal que dicha tutela no resulta retórica, sino práctica. ${ }^{12}$

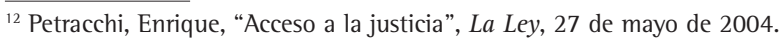


Este instituto se encuentra descrito en nuestra Constitución Nacional en el derecho a peticionar ante las autoridades (Art. 14 de la cN) y entre las autoridades se encuentra el poder judicial, pero el tener acceso a la justicia no finaliza su obligatoriedad constitucional, sino además que se respete la tutela judicial efectiva, es decir, que verdaderamente llegue en tiempo razonable y sin limitaciones sociales, culturales y económicas.

\subsection{CuÁles SON LOS OBSTÁCULOS Y PROBLEMÁtICAS PRINCIPALES PARA ACCEDER A LA JUSTICIA}

Una investigación realizada recientemente por la FESPAD, ${ }^{13}$ a través de entrevistas con operadores (jueces, procuradores, fiscales, abogados, comunidades, sindicatos y otros sectores) reveló que los principales problemas en esta materia son los siguientes:

a) La pobreza, por las limitaciones económicas para contratar un abogado/a particular y por los costos que le representa movilizarse de un lugar a otro.

b) La falta de confianza en las instituciones del sector justicia, que puede ser generada por la nula o poca atención por parte de las funcionarios(as) y empleados(as) públicos, la falta de resultados efectivos cuando hizo uso de las instituciones o la falta de información sobre las mismas.

c) El desconocimiento por parte de la población de sus derechos y de los roles de las instituciones.

d) La retardación de justicia.

e) La persistencia de la corrupción en las instituciones y operadores sobre todo evidenciada por casos de tráfico de influencias.

f) Los costos onerosos y la falta de garantías para contratar un abogado particular.

g) Procedimientos engorrosos y poco efectivos.

h) Falta de recursos materiales, humanos y financieros en algunas instituciones para satisfacer la necesidad de la población usuaria.

i) La carga de trabajo de las instituciones y la falta de idoneidad del personal.

Como podemos apreciar, de los nueve puntos que describen los obstáculos del acceso a la justicia, tres de ellos se relacionan con la problemática socialeconómica. Éste no es un tema menor, porque se estaría comprobando que

${ }^{13}$ Fundación de Estudios para la Aplicación del Derecho, en Salvador, octubre de 2004. 
la justicia no cumple su rol esencial de que todos tengan acceso sin restricciones y en un plano de igualdad ante un juez imparcial e independiente.

\subsection{La contraloría social para la defensa del accCeso a la Justicia}

Para la FESPAD, los problemas de acceso a la justicia sólo podrán superarse con un adecuado ejercicio de la contraloría social. Entendiendo ésta como "la facultad política de personas o grupos para ejercer vigilancia, exigencia, control, monitoreo o evaluación del poder ejercido por funcionarios o instituciones públicas o privadas para contribuir, incidir o garantizar una administración pública sujeta a la ley y respetuosa de los derechos humanos".

La FESPAD constituyó recién un área de trabajo en el campo de la contraloría social para la defensa del acceso a la justicia. Dicha área responde a la necesidad de realizar esfuerzos complementarios a los que desde hace años viene realizando la institución en materia de promoción y defensa de los derechos humanos.

Se ha constatado que la formación y sensibilización de la población en materia de derechos humanos, queda incompleta si la misma no es dotada de herramientas para enfrentarse a los obstáculos que se presentan al querer exigir sus derechos. La FESPAD había venido realizando una labor de acompañamiento y procuración jurídica, pero enfrentando los obstáculos que supone el ingreso al sistema judicial.

En este sentido la FESPAD, a través del Centro de Estudios Constitucionales y Derechos Humanos ( promoción de la contraloría social en la defensa del acceso a la justicia. Eso supone una labor de vigilancia social de las políticas o programas relacionados con la justicia y de la labor cotidiana de las instituciones del sector. ${ }^{14}$

Se han planteado dos líneas de acción:

- La constitución de tres "Centros de defensa de acceso a la justicia", ubicados en las principales zonas del país, que se encargarán de asesorar, recibir denuncias y acompañar a las víctimas para la erradicación de los obstáculos cuando se enfrenten al sistema judicial.

- La creación de "Comités ciudadanos de defensa del acceso a la justicia”, que son grupos previamente organizados (directivas comunitarias,

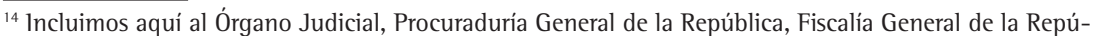
blica, Procuraduría para la Defensa de los Derechos Humanos y Policía Nacional Civil. 
comunidades, grupos de víctimas asociadas) o un grupo social que quiera formar un comité específico para la defensa del acceso a la justicia.

\subsection{Situación en América}

Estudios sobre percepción del usuario, realizados por el Instituto Gallup en Argentina, el Centro de Estudios Públicos en Chile y el Tribunal Superior de Justicia de Costa Rica, calificaron a la justicia en general como mala, insatisfactoria, lenta e inoportuna. Allí se destacaron los aspectos negativos, como lentitud, burocracia, privilegio para los ricos, corrupción, impunidad, dependencia, injusticia y politización, además de la existencia de leyes blandas y desactualizadas.

Chile cuenta con un sistema de asistencia jurídica orientado a la población que no puede procurársela por sí misma, que abarca casi todas las materias, utiliza diversas formas de intervención y tiene presencia en todo el país.

Costa Rica presenta la Defensa Pública que "mejor ha funcionado históricamente" en la región, gracias a "programas especiales para poblaciones desfavorecidas, en especial a las personas privadas de libertad".

En tanto, en Colombia se promueve el programa Casas de Justicia en todo el territorio, para desconcentrar los servicios judiciales y promover las mediaciones en la resolución de litigios.

Las mayores dificultades de orden jurídico en la región se encuentran en América Central: Bolivia, Ecuador y Paraguay, donde "con dificultad se atiende a la población imputada en materia penal mediante defensa pública, pero no existe cobertura en otras áreas".

La pobreza es el principal factor de segregación y exclusión en la justicia latinoamericana. Le siguen la formación paternalista de jueces y abogados, el elitismo de juristas, el desconocimiento de los derechos y las formas de ejercerlos por los ciudadanos y la nula intervención de líderes de la sociedad civil en la resolución de conflictos, según la evaluación en marcha. Se agregan la discriminación contra la mujer, el desconocimiento del derecho indígena y de la cosmovisión de los pueblos originarios del continente, el costo económico, trámites burocráticos, y las barreras lingüisticas y culturales. La escrituración, formalización y secreto de los procedimientos impiden la transparencia, comprensión y la total participación de las partes en sus procesos. ${ }^{15}$

\footnotetext{
${ }^{15} \mathrm{http}: / /$ www.cumbresiberoamericanas.com/principal
} 


\subsection{La Unión Europa y la nueva ley $16 / 05$ española}

La apertura que para los países de la Unión Europea ha supuesto la consagración de un mercado único en el que circulan libremente personas, mercancías, servicios y capitales podría considerarse incompleta si no fuera acompañada de un sistema de garantías que asegurase a los ciudadanos europeos la tutela de sus derechos en dicho ámbito.

Es por ello que la tutela judicial efectiva consagrada en el artículo 47 de la Carta de los Derechos Fundamentales de la Unión Europea, debe también extenderse a los litigios transfronterizos originados por el funcionamiento del mercado único.

Esta tutela judicial efectiva tiene una importante manifestación en la llamada justicia gratuita, cuyo sentido último obedece a la necesidad de que la carencia de recursos económicos no actúe como filtro de las posibilidades de acceso a la justicia por parte de los ciudadanos. Para paliar tal situación, varios países europeos han creado, ya desde antiguo, los llamados "beneficios de pobreza", "beneficio de gratuidad de la justicia", "derecho de justicia gratuita", o también, "derecho de asistencia jurídica gratuita".

Al respecto la Directiva 2003/8/cE responde al propósito de la Unión Europea, declarado en el Consejo Europeo de Tampere de 15 y 16 de octubre de 1999, de instaurar unas normas mínimas que garanticen un nivel adecuado de justicia gratuita para los asuntos transfronterizos en el conjunto de la Unión. Tales litigios transfronterizos serían, de acuerdo con la definición ofrecida por la propia Directiva 2003/8/CE, aquellos en los que la parte que solicita la justicia gratuita está domiciliada o reside habitualmente en un Estado miembro distinto de aquel otro Estado miembro donde se halle el tribunal competente para su conocimiento o en el que deba ejecutarse la resolución.

Por su parte, la Constitución española en su artículo 119 dispone que la justicia sea gratuita cuando así lo disponga la ley y, en todo caso, respecto de quienes acrediten insuficiencia de recursos para litigar. De acuerdo con la jurisprudencia del Tribunal Constitucional (puesta de manifiesto en sentencias como la 30/1981, 77/1983 o 216/1988), la gratuidad de la justicia se configura como un derecho subjetivo cuya finalidad es asegurar la igualdad de defensa y representación procesal al que carece de medios económicos, constituyendo al tiempo una garantía para los intereses de la justicia. 
En España, la regulación de esta materia se encuentra en la importante Ley 1/1996, de 10 de enero, de Asistencia Jurídica Gratuita, la cual puso fin a la dispersión normativa hasta entonces existente y tuvo como principal novedad la desjudicialización del procedimiento del reconocimiento de este derecho. Una ley que ahora debe modificarse para incorporar al ordenamiento jurídico la Directiva 2003/8/ce del Consejo, de 27 de enero de 2003, destinada a mejorar el acceso a la justicia en los litigios transfronterizos mediante el establecimiento de reglas mínimas comunes relativas a la justicia gratuita para dichos litigios, a través de la Ley 16 de 2005.

Esta nueva norma incluye en el ámbito de aplicación de la ley a tales personas con discapacidad y a quienes las tengan a su cargo, así como a las asociaciones que tengan como finalidad la protección de personas con discapacidad.

También aquí se aprovecha para reconsiderar algunos aspectos generales de la tramitación de las solicitudes de reconocimiento del derecho, que en la práctica venían perjudicando la efectividad de la tutela judicial que la Constitución consagra. Tal es el caso de la consideración de la suspensión de los plazos no sólo de prescripción, sino también de caducidad de las acciones con anterioridad al inicio del proceso, y también la ampliación de los plazos con que cuentan abogados y colegios de abogados en los supuestos de insostenibilidad de las pretensiones, y que resultaban manifiestamente insuficientes en los supuestos de mayor complejidad.

Asimismo, frente al reconocimiento en la Ley 1/1996, de 10 de enero, del acceso gratuito a todo tipo de procesos a quienes acrediten insuficiencia de medios para litigar, comprendiendo no sólo personas físicas, sino también a determinadas personas jurídicas (asociaciones de utilidad pública y fundaciones inscritas en el registro administrativo correspondiente), la Directiva 2003/8/CE se limita a reconocer el derecho a la justicia gratuita a las personas físicas y únicamente en los procesos en materia civil y mercantil.

Sin embargo, en este ámbito la directiva contempla algunas prestaciones puntuales que nuestra legislación no recoge, como son los servicios de interpretación, la traducción de documentos presentados por el beneficiario a instancia del tribunal o autoridad competente y que sean necesarios para resolver el asunto, o gastos de desplazamiento que corran por cuenta del solicitante del derecho, si bien a este respecto habrá de tenerse en cuenta lo dispuesto en el Reglamento (CE) 1206/2001 del Consejo, de 28 de mayo de 2001, relativo a la cooperación entre los órganos jurisdiccionales 
de los estados miembros en el ámbito de la obtención de pruebas en materia civil o mercantil.

Debe precisarse que la delimitación del ámbito objetivo de los litigios transfronterizos en torno a los procesos en materia civil y mercantil, comprende también los litigios derivados de un contrato de trabajo, de conformidad con lo dispuesto en el Reglamento (CE) 44/2001 del Consejo, de 22 de diciembre de 2000, relativo a la competencia judicial, el reconocimiento y la ejecución de resoluciones judiciales en materia civil y mercantil. La Ley 1/1996, de 10 de enero, ya reconoce con carácter general la justicia gratuita a los trabajadores, que ahora verían ampliado el contenido de su derecho con las novedades que introduce el nuevo capítulo viII de esta ley para los litigios transfronterizos.

\section{JERARQUIZACIÓN ENTRE LOS DERECHOS ECONÓMICOS, SOCIALES Y CULTURALES Y LOS DERECHOS CIVILES Y POLÍTICOS}

Norberto Bobbio ${ }^{16}$ señala que: "La razón de ser de los derechos sociales como la educación, el derecho al trabajo, el derecho a la salud, es una razón igualitaria. Los tres tienden a hacer menos grande la desigualdad entre quienes tienen y quienes no tienen, o para poner un número de individuos siempre mayor en condiciones de ser menos desiguales respecto a individuos más afortunados por nacimiento o condición social."

La doctrina distingue los derechos civiles y políticos de los derechos económicos, sociales y culturales en que estos últimos implican, necesariamente, obligaciones de acción y no de omisión, como las demandan los primeros, en relación con las personas.

Cançado Trindade ${ }^{17}$ parte del concepto de indivisibilidad de los derechos humanos, afirmando que entre los derechos individuales y los sociales no puede haber sino complementariedad e interacción y no compartimentación y antinomia. El autor continúa explicando el desarrollo de los derechos económicos, sociales y culturales tanto en el sistema europeo como en el interamericano.

Realizar una jerarquización de derechos per se resulta una herramienta sumamente peligrosa por considerar de antemano situaciones que deben resolverse al caso concreto por los jueces de la causa.

${ }^{16}$ Bobbio, Norberto, Derecha e izquierda, Taurus, España, 1995, p. 151.

${ }^{17}$ Cançado Trindade, Antônio Augusto, "La justiciabilidad de los derechos económicos, sociales y culturales en el plano internacional”. 
Dado que ideológicamente concebimos a la democracia como un sistema de inclusiones, no de exclusiones, ${ }^{18}$ y porque compartimos con Scheinin ${ }^{19}$ la idea de que los derechos económicos, sociales y culturales son una parte esencial del código normativo internacional de los derechos humanos (además de que así ha sido inequívocamente establecido en los Principios de Limburgo sobre la Aplicación del Pacto Internacional de Derechos Económicos, Sociales y Culturales), juzgamos de real valía que se concrete el pasaje de la progresividad simbólica a la progresividad efectiva y real de tal tipología de derechos, principio de progresividad que interactúa con el de no progresividad.

\section{El SOLVE ET REPETE}

El solve et repete es un instituto por el cual se condiciona el accionar judicial de los derechos tributarios o previsionales controvertidos, a su pago previo.

Su origen etimológico deriva del latín y su traducción literal sería: paga y reclama (repite), inspirado en la ejecutoriedad de las resoluciones administrativas.

En la Argentina, la aplicación del solve et repete en el ámbito impositivo fue producto de una creación pretoriana de la Corte Suprema de Justicia de la Nación en antecedentes muy lejanos. ${ }^{20}$

En la actualidad resulta un instituto muy discutido y, tanto en la doctrina como en la jurisprudencia especializada internacional, no se establecen en forma clara y precisa sus alcances.

Chiovenda, ${ }^{21}$ por ejemplo, lo ha reputado como una excepción procesal puesta en favor de la actividad fiscal del Estado. Mortara, Bielsa y Jarach ${ }^{22}$ encuentran su sustento jurídico en la presunción de legitimidad y de ejecutoriedad de los actos administrativos, de los que se derivaría, a su juicio, la

\footnotetext{
${ }^{18}$ Valadés, Diego, Constitución y política, Instituto de Investigaciones Jurídicas, Universidad Nacional Autónoma de México, México, 1994, pp. 23-24

${ }^{19}$ Scheinin, Martin, "Economic and social rights as legal rights", en Eide, Asbjørn, Economic, social and cultural rights, Dordrecht, Boston, 1995, citado por Rodríguez Pinzón, Diego, Martín, Claudia y Ojea Quintana, Tomás, La dimensión internacional de los derechos humanos, Banco Interamericano de Desarrollo-American University, Washington Dc, 1999, p. 362.

${ }^{20}$ Fallos 17:207, 31:103 y 79:17.

21 "Ensayos de derecho procesal civil: relación procesal de cognición; sentencia, juicios de impugnación, litispendencia y cosa juzgada - relaciones procesales con intereses múltiples - relación procesal de ejecución. Ed. Jurídicas Europa-América, Bs. As., 1949.

22 Jarach, Dino, Finanzas públicas y derecho tributario, Edit. Cangallo, 1982.
} 
procedencia de no suspender los efectos de una determinación impositiva hasta que se abone el tributo o se logre su revocación en sede judicial. ${ }^{23}$

Giuliani Fonrouge, ${ }^{24}$ por su parte, ha aunado ambas posturas, al añadir al argumento de la presunción de legitimidad y ejecutoriedad del acto administrativo la necesidad de asegurar la recaudación, recordando al respecto que para la doctrina italiana el solve et repete constituía un privilegio del fisco orientado a evitar dilaciones en la recaudación de los tributos.

En la causa "Aserradero Clipper SRL", ${ }^{25}$ el máximo tribunal estableció que "los tributos públicos, de acuerdo a la regla solve et repete, sólo son impugnables previo pago. Dicha regla no impide la discusión de cuestiones de constitucionalidad, en juicios contradictorios ejecutivos o de apremio, siempre que se demuestre satisfactoriamente la imposibilidad del pago del gravamen." ${ }^{26}$

En materia previsional, ha fijado en el conocido caso "Microómnibus Barrancas de Belgrano SA" ${ }^{27}$ que la obligación del previo depósito para la impugnación de una decisión administrativa en materia previsional no resultaba violatorio de la norma precitada, toda vez que el apelante ni siquiera ha alegado que le fuera imposible interponer el recurso de apelación previsto en la legislación cuestionada, debido al excesivo monto del depósito, de tal forma impedir real y efectivamente el ejercicio de su derecho.

No obstante ello, la Corte en la causa "Sanatorio Otamendi" admitió el recurso deducido por esas empresas aun cuando no se había acreditado que el pago previo de sus deudas previsionales resultara económicamente imposible de cumplir. Efectivamente, en virtud de la magnitud de su monto el depósito exigido ocasionaría un perjuicio irreparable a la entidad asistencial -ya que ni siquiera vendiendo el edificio en el que se ubica su sede sería posible efectuar el pago, según adujo.

En mi opinión, nos hallamos frente a un choque de derechos constitucionales de marcada trascendencia sin solucionar; por el lado de los contribuyentes se encuentran los derechos de igualdad, de defensa en juicio, de acceso a la justicia y de tutela judicial efectiva -para utilizar terminología de la Constitución española y de la Convención Americana

${ }^{23}$ Barreiro, Rafael F. L., "Algunas reflexiones sobre la constitucionalidad del solve et repete", LL, pp. 1991-2060.

${ }^{24}$ Giuliani Fonrouge, Derecho financiero, Edit. Depalma, 1982.

${ }^{25}$ CSJN , "Aserradero Clipper SRL", del 01/01/61, Fallo 249:221.

${ }^{26}$ Fallos 31:103; 161:328; 178:266, entre otros.

${ }^{27}$ Fallo 312:2490 
de Derechos Humanos o Pacto de San José de Costa Rica- y por otro lado la renta del Estado, cuya recaudación fiscal resulta de vital importancia para el cumplimiento de sus fines específicos.

Ello así, el camino más correcto a seguir no podría ser otro que la búsqueda del equilibrio, ya que resultaría extremadamente injusto inclinarnos por la derogación o la utilización lisa y llana del solve et repete, porque, como ya se dijo, los derechos en juego son muy delicados. Por lo tanto, estoy plenamente convencido de que el único elemento armonizador de los derechos es la utilización por vía incidental de un instituto que denominaré "beneficio de litigar sin pago previo del tributo" o "beneficio de litigar sin solve et repete", en donde se buscará una protección equilibrada entre los derechos de los contribuyentes y del fisco nacional. ${ }^{28}$

El juez, en cada caso concreto, debe apreciar la necesidad de la reclamación, así como la carencia de capacidad contributiva para hacer frente al pago previo pretendido por el ente recaudador. En el caso en que se resuelva a favor del beneficiario, se suspenderá durante la tramitación del procedimiento el cumplimiento de su obligación fiscal, siempre y cuando durante el proceso no mejore su capacidad contributiva o no se resuelva en forma contraria la acción principal, dado el carácter de provisoriedad del incidente en cuestión.

\section{LIMITACIONES ECONÓMICAS VEDADAS Y PERMITIDAS}

De acuerdo con todo lo visto precedentemente debemos decir que no puede existir ningún tipo de restricciones al acceso a la justicia, ni sociales, ni culturales, ni económicas, donde todas las personas puedan obtener una sentencia en condiciones de igualdad. Todo ello como política económica del Estado.

A pesar de ello, en países subdesarrollados como el nuestro, donde el factor económico es escaso con un alto índice de evasión fiscal, ${ }^{29}$ la

\footnotetext{
${ }^{28}$ Maraniello, Patricio, "El incidente de beneficio de litigar sin solve et repete", Revista de Derecho Público, Rubinzal Culzoni, 2004.

${ }^{29}$ Sabido es que la solución a esta cuestión no resulta fácil, si se tiene en cuenta el frágil sistema recaudatorio y la gran evasión fiscal que sufre la Argentina (actualmente la evasión ronda en los cuarenta mil millones de pesos anuales). El administrador federal de lngresos Públicos, Alberto Abad, insistió en que el organismo a su cargo está detrás de los evasores. Para dejarlo en claro, el primer paso que dio fue poner en internet, en el sitio oficial, todas las denuncias penales iniciadas desde el 1 de enero y hasta el 30 de junio últimos. En ese lapso, dijo Abad, contabilizan 647 las causas iniciadas por un monto total de 132 millones de pesos. Si al engorroso proceso administrativo y judicial, donde el contribuyente utiliza todas las armas dilatorias posibles para no cumplir con su obligación fiscal, se deja sin efecto también
} 
igualdad debe darse desde otra óptica, donde los que pueden contribuir al sostenimiento del Estado deban hacerlo para que aquellas personas que no puedan contribuir accedan a los servicios públicos mínimos, que son básicamente: agua, salud, educación, seguridad y justicia.

Aquí lo que quiero destacar es que el amplio acceso a la justicia es solamente para las personas de escasos recursos y restringida para las personas que tienen capacidad contributiva para el pago de la tasa de justicia. Para este último caso, se invierte la carga de la prueba, es decir, es la parte demandada o el fisco quien deberá demostrar que la parte actora puede pagar la tasa de justicia respectiva.

Y sólo en cuestiones de reclamos judiciales en materia tributaria se deberá aplicar -según lo señalado en el punto anterior- el incidente de beneficio de litigar sin solve et repete, para que de este modo se le dé la oportunidad de demostrar la carencia de capacidad contributiva para el pago del tributo reclamado.

Por otro lado, se evita aumentar el alto índice de evasión tributario que hoy existe en Argentina, atento que si no existe alguna limitación al reclamo tributario, con el sólo hecho que una persona presente una apelación en la justicia y en las instancias posteriores es suficiente para no pagar la carga tributaria correspondiente.

A los efectos de implementar estas propuestas, deberá modificarse la ley de tasa de justicia 23898 y el incidente de beneficio de litigar sin gastos, regulado en los artículos 78 al 86 del CPCCN, por un procedimiento incidental que sólo se podrá abrir si el fisco o el propio juez alegase elementos fácticos y jurídicos por los cuales pueda verosímilmente considerarse que una persona está en condiciones de afrontar el pago de la tasa de justicia correspondiente, y es en este caso la propia parte quien deberá pagar el tributo o realizar su descargo en contrario.

La solución que se brinda en esta ocasión es para que todos tengan acceso a la justicia y el poder judicial pueda tener recurso propio y genuino para su funcionamiento independiente.

la regla solve et repete, el problema recaudatorio se potenciaría aún más. Así pues, la recaudación impositiva del Estado quedaría supeditada a que los contribuyentes no presentaran acción o recurso alguno, circunstancia ésta que entorpeceria la recaudación fiscal, pues permitiría a los contribuyentes eludir el pago del tributo, estando en condiciones económicas para abonarlo y más aún encontrándose legalmente obligado a satisfacerlo. 


\section{A MOdO DE CONCLUSIÓN}

Pudimos notar a lo largo de este trabajo, la importancia que reviste tanto el acceso a la justicia como las políticas económicas en un país donde la buena elección de ella lleva a su prosperidad y su crecimiento, mientras que un error en dicha selección producirá serias desavenencias sociales.

Hoy, al tener todas las escuelas económicas en nuestra Constitución -liberal, social e internacionalista-, podemos decir que la elección de una correcta política económica judicial es lo que en definitiva inclinará en mayor o en menor medida la prosperidad de la nación, porque la misma Constitución es la que lo permite, mientras que no se violen derechos y garantías constitucionales.

Según estudios sobre percepción del usuario, realizados por el Instituto Gallup en Argentina, el Centro de Estudios Públicos en Chile y el Tribunal Superior de Justicia de Costa Rica, calificaron a la justicia en general como mala, insatisfactoria, lenta e inoportuna. Ante este marco de situación, América ha tratado de solucionar estas falencias por diferentes medios: Chile con "Asistencias jurídicas gratuitas"; Costa Rica con "Defensorías Públicas", Colombia con el "Programa de Casa de Justicia" y Argentina con "Defensorías públicas y asistencia jurídica gratuita".

En este mismo sentido, El Salvador creó la "contraloría social" en la defensa del acceso a la justicia. Eso supone una labor de vigilancia social de las políticas o programas relacionados con la justicia y la labor cotidiana de las instituciones del sector justicia, por medio de ellas y los propios ciudadanos.

Sin embargo, resulta conveniente que la búsqueda se centre en la correcta interpretación y aplicación del derecho de una de las partes -el fisco nacional o provincial-, sin destruir o limitar los derechos de la otra -el justiciable-, a menos que esta limitación sea netamente justa y razonable, es decir, que su derecho a la jurisdicción se vea limitado por la propia voluntad del peticionante en no pagar el tributo estando en condiciones económicas de hacerlo, luego que el juez después de un serio y pormenorizado análisis resuelva en el beneficio de litigar sin solve et repete en caso de reclamos tributarios y por vía incidental en los restantes, el pago de la tasa de justicia.

En mi opinión, no resulta adecuado la aplicación lisa, llana y absoluta de uno de los derechos en juego, es decir, no es conveniente aplicar una justicia absoluta a todas estas cuestiones, sino por el contrario una justicia 
equitativa que equilibre tanto los derechos al acceso a la justicia de todas las personas y los recursos propios que necesita el poder judicial, elemento este último que hace a su independencia e igualdad entre los restantes poderes del Estado.

Juan Bautista Alberdi sostenía: "No poder costear su gobierno, es exactamente no tener medios de ejercer su soberanía, es decir, no poder existir independientemente, no poder ser libre." ${ }^{30}$

Ella es la misma igualdad, justicia equitativa e independiente que requieren todos los hombres y mujeres de nuestro país, porque de otro modo se verá como ultrajada la soberanía popular.

${ }^{30}$ Alberdi, Juan Bautista, Op. cit. 